\title{
Oropharyngeal Chlamydia trachomatis in women; spontaneous clearance and cure after treatment (FemCure)
}

\author{
Citation for published version (APA):
}

Dukers-Muijrers, N. H. T. M., Wolffs, P., Lucchesi, M., Gotz, H. M., De Vries, H., van der Loeff, M. S., Bruisten, S. M., \& Hoebe, C. J. P. A. (2021). Oropharyngeal Chlamydia trachomatis in women; spontaneous clearance and cure after treatment (FemCure). Sexually Transmitted Infections, 97(2), 147151. https://doi.org/10.1136/sextrans-2020-054558

Document status and date:

Published: 01/03/2021

DOI:

10.1136/sextrans-2020-054558

\section{Document Version:}

Publisher's PDF, also known as Version of record

\section{Document license:}

Taverne

\section{Please check the document version of this publication:}

- A submitted manuscript is the version of the article upon submission and before peer-review. There can be important differences between the submitted version and the official published version of record. People interested in the research are advised to contact the author for the final version of the publication, or visit the DOI to the publisher's website.

- The final author version and the galley proof are versions of the publication after peer review.

- The final published version features the final layout of the paper including the volume, issue and page numbers.

Link to publication

\footnotetext{
General rights rights.

- You may freely distribute the URL identifying the publication in the public portal. please follow below link for the End User Agreement:

www.umlib.nl/taverne-license

Take down policy

If you believe that this document breaches copyright please contact us at:

repository@maastrichtuniversity.nl

providing details and we will investigate your claim.
}

Copyright and moral rights for the publications made accessible in the public portal are retained by the authors and/or other copyright owners and it is a condition of accessing publications that users recognise and abide by the legal requirements associated with these

- Users may download and print one copy of any publication from the public portal for the purpose of private study or research.

- You may not further distribute the material or use it for any profit-making activity or commercial gain

If the publication is distributed under the terms of Article $25 \mathrm{fa}$ of the Dutch Copyright Act, indicated by the "Taverne" license above, 


\title{
Oropharyngeal Chlamydia trachomatis in women; spontaneous clearance and cure after treatment (FemCure)
}

\author{
Nicole H T M Dukers-Muijrers (D) , 1,2 Petra Wolffs, ${ }^{3}$ Mayk Lucchesi, ${ }^{3}$ \\ Hannelore M Götz (D) , 4,5 Henry De Vries, 7,8 Maarten Schim van der Loeff, 7,9 \\ Sylvia M Bruisten (1D) ${ }^{7,8}$ Christian J P A Hoebe $2,3,10$
}

For numbered affiliations see end of article.

\section{Correspondence to} Dr Nicole H T M DukersMuijrers, Department of Health Promotion, University of Maastricht, CAPHRI, Maastricht, The Netherlands; nicole. dukers@ggdzl.nl

Received 22 April 2020 Revised 17 June 2020 Accepted 27 June 2020 Published Online First 31 July 2020

Check for updates

(C) Author(s) (or their employer(s)) 2021. No commercial re-use. See rights and permissions. Published by BMJ.

To cite: DukersMuijrers NHTM,

Wolffs P, Lucchesi M,

et al. Sex Transm Infect

2021:97:147-151

\section{ABSTRACT}

Objectives Women attending STI clinics are not routinely tested for oropharyngeal Chlamydia trachomatis (CT) infections. We aimed to assess spontaneous clearance of oropharyngeal CT and cure after antibiotic treatment in women.

Methods Women with vaginal or rectal CT $(n=560)$ were recruited at STI clinics in 2016-2017, as part of the FemCure study (prospective cohort study). We included participants' data from week -1 , that is, the diagnosis at initial visit, when clinics applied selective oropharyngeal testing. At week -1, a total of 241 women were oropharyngeally tested (30 positive) and 319 were untested. All FemCure participants provided nurse-collected oropharyngeal samples at study enrolment, that is, week 0 , just prior to treatment $(n=560)$, and after treatment at weeks $4(n=449), 8(n=433)$ and $12(n=427)$. Samples were tested by nucleic acid amplification test, and at week 0 also by viability testing by viability PCR. Proportions of oropharyngeal CT test results were presented to represent spontaneous clearance and cure.

Results of 30 women diagnosed with oropharyngeal $\mathrm{CT}$ at week -1, fifteen (50\%) were negative at week 0 after a median of 9 days, that is, 'spontaneous clearance'. At week 0 , a total of 560 participants were tested, and 46 (8.8\%) were oropharyngeal CT positive; 12 of them (26.1\%) had viable CT. Of the 46 positive, 36 women had an oropharyngeal test after treatment; $97.2 \%$ (35/36) were negative at week 4, that is, 'cure'. Of all women with follow-up visits, the proportion of oropharyngeal CT positive was between $0.5 \%$ and $1.6 \%$ between weeks 4 and 12. Of those not tested at week $-1(n=319), 8.5 \%$ $(n=27)$ were oropharyngeal positive at week 0 .

Conclusions The clinical importance of oropharyngeal CT in women is debated. We demonstrated that spontaneous clearance of oropharyngeal CT among women is common; of those who did not clear for CT, three-quarters had non-viable CT. After regular treatment with azithromycin or doxycycline, cure rate $(97 \%)$ of oropharyngeal CT is excellent.

Trial registration number NCT02694497.

\section{INTRODUCTION}

Chlamydia trachomatis (CT) infection is the most commonly reported treatable bacterial STI in highincome countries. ${ }^{12}$ CT disproportionally affects women, who may develop pelvic inflammatory disease, ectopic pregnancy, tubal infertility and chronic abdominal pain. ${ }^{34}$ CT can occur at the vaginal site, the rectal site and the oropharyngeal site. The prevalence of oropharyngeal CT is $0.2 \%$ $3.2 \%$ (median 1.7\%) in women, 0\%-3.6\% (median $1.7 \%$ ) in men who have sex with men (MSM) and $0 \%-22.0 \%$ (median 1.6\%) among men who have sex with women. ${ }^{5}$ Oropharyngeal CT may frequently occur as a single infection (thus without genital or rectal CT); this was the case in 53\% of 148 MSM and $32 \%$ of 164 women, selectively tested, at the STI clinic in Amsterdam. ${ }^{6}$ Data on oropharyngeal CT in women are scarce as women are not routinely tested for oropharyngeal CT, while in MSM oropharyngeal testing is an emerging practice. ${ }^{5}$ Oropharyngeal CT infections have been considered low bacterial load infections ${ }^{7}$ that are frequently self-limiting. ${ }^{68}$ Concerns were raised that oropharyngeal CT infection may initiate a reservoir of infection, that is, via the gastrointestinal tract. ${ }^{9}$ To date, the role of oropharyngeal CT in further CT transmission or in the capacity to cause clinically relevant infections is unclear, and thereby the need for oropharyngeal testing in women is debated. ${ }^{10}$

As part of the FemCure study, ${ }^{11}$ we followed women diagnosed with vaginal or rectal CT in routine STI clinic care, and have taken the opportunity to also assess oropharyngeal CT over time. We evaluated clearance of oropharyngeal CT between diagnosis and treatment (ie, spontaneous clearance), clearance of oropharyngeal CT at 4 weeks after treatment (ie, cure) and the occurrence of oropharyngeal CT up to 12 weeks after regular treatment for rectal or vaginal CT. In addition, next to assessing CT-DNA positivity, we assessed the CT viability.

\section{METHODS}

\section{Study design}

This is a prospective cohort study, as part of the FemCure study. ${ }^{11}$ The study was conducted at three STI clinics of the Public Health Services South Limburg, Rotterdam-Rijnmond and Amsterdam, which together conduct almost half of all STI clinic consultations in the Netherlands. We include data from participants' clinic diagnosis visit, before enrolment at week -1 , when selective oropharyngeal 


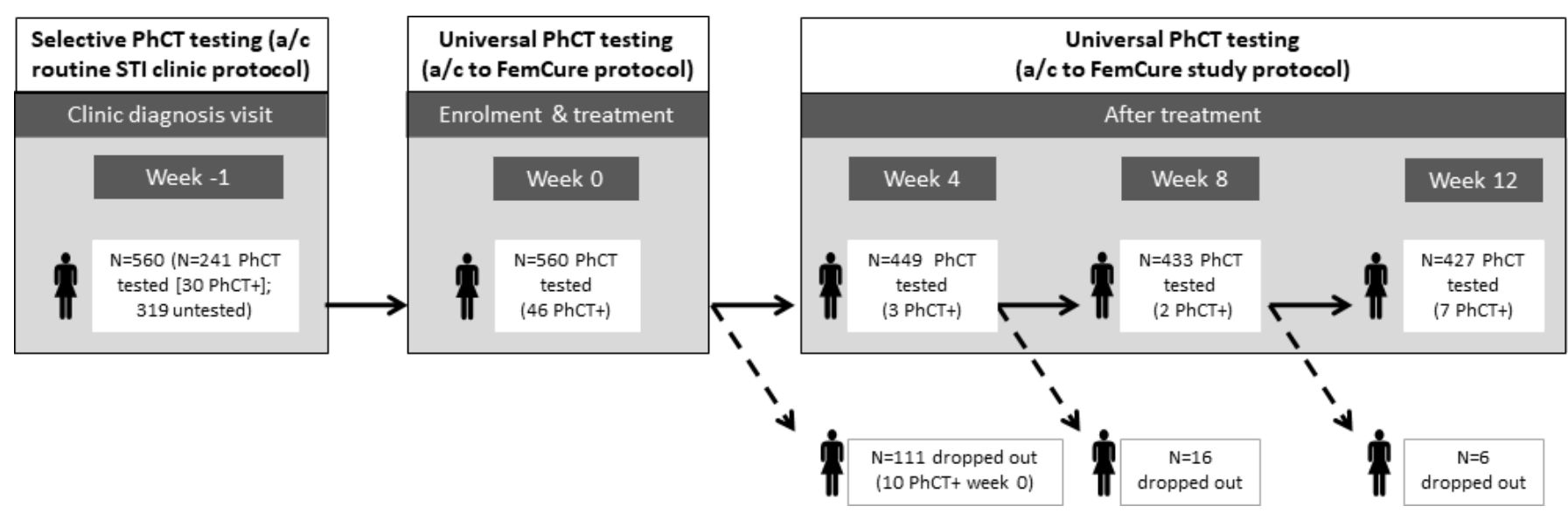

Figure 1 Design of the study and number of participants at each time point. CT, Chlamydia trachomatis; Ph, oropharyngeal.

testing was applied per routine care protocol; based on being a sex worker, being notified or orally exposed as indication for oropharyngeal testing, as oropharyngeal screening is not standardly recommended in women. ${ }^{12}{ }^{13}$ Oropharyngeal tested women, in most cases, reported unprotected sex with a casual partner. Clinics applied the same procedures using different nucleic acid amplification tests (NAAT) with comparable high sensitivity for diagnostic testing. ${ }^{13}$ Women who, at week -1 , were diagnosed with a vaginal or a rectal CT infection between April 2016 and September 2017 could be included in the study, at week 0 , when they returned to the clinic for treatment, on the day of and just prior to treatment. Treatment was according to regular care protocol ${ }^{12}$; that is, either by a 7 -day course of doxycycline $100 \mathrm{mg}$ orally twice daily or a $1 \mathrm{~g}$ single oral dose of azithromycin; treatment choice was not based on the oropharyngeal CT test result. At study enrolment, at STI clinic visits at week 0, just prior to treatment for vaginal or rectal CT, and at weeks 4, 8 and 12 after treatment, study nurses collected oropharyngeal samples (swab) from participants. As these study samples were tested afterwards, participants were untreated for oropharyngeal CT during follow-up. At week 12, women received a routine STI clinic check-up including oropharyngeal testing and treatment when needed. Some women became lost to follow-up (figure 1).

\section{Sample processing}

Two swabs were collected at week 0 . A first sample was collected for viability testing and a second sample was collected for CT-DNA testing. The sample for viability testing was placed in $4 \mathrm{~mL}$ sucrose phosphate transport buffer and immediately stored at $-80^{\circ} \mathrm{C}$ to maintain $\mathrm{CT}$ viability until laboratory analysis. The sample for CT-DNA testing was placed in COBAS buffer and used to test for CT-DNA with PCR (Roche Cobas 4800, Roche Diagnostics, Basel, Switzerland), according to manufacturers' guidelines. Second, swabs were placed in COBAS buffer for testing with quantitative PCR testing, detecting CT-DNA (Roche Cobas 4800, Roche Diagnostics), according to manufacturers' guidelines. Of the women who tested positive in NAAT at week 0 , samples were subsequently tested for viability with viability PCR (V-PCR). A positive V-PCR test indicates presence of CT-DNA from intact (ie, viable) CT organisms. ${ }^{14}{ }^{15}$ Week 4,8 and 12 samples were tested by NAAT.

\section{Definitions and statistical analyses}

Spontaneous clearance: when a woman was diagnosed by NAAT with oropharyngeal CT at week -1 , and tested negative by NAAT for oropharyngeal CT when she returned for treatment at week 0 .
Cure: when a woman who tested positive by NAAT for oropharyngeal CT at week 0 , just prior to treatment, tested oropharyngeal CT negative by NAAT at week 4 after treatment.

We present spontaneous clearance and cure as proportions. We also present the test results at each study visit, and viability test result at week 0 as proportions. We used SPSS Statistics V.24 (IBM) for descriptive statistics.

\section{RESULTS}

At week -1 , five hundred and thirty-one women were diagnosed with vaginal CT and 184 with rectal CT. Two hundred and forty-one women were also tested for oropharyngeal CT and 30 women were diagnosed with oropharyngeal CT. Three hundred and nineteen women were not oropharyngeal tested (figure 1). Median age was 22 years (IQR was 20-24).

\section{Spontaneous clearance between clinic diagnosis at week -1 and treatment at week 0}

The median interval between the week -1 and week 0 visits was 9 days (IQR: 7-12). In the 30 women diagnosed with oropharyngeal CT at week -1 , spontaneous clearance at week 0 was observed in 15 (50\% (95\% CI 31.3\% to 68.7\%)) (table 1).

\section{Cure at week 4 post-treatment}

Of the 46 women who were CT positive at week 0 , thirty-six were tested at week 4. Cure (ie, NAAT negative at week 4) was observed in 35 (97.2\% (95\% CI $85.5 \%$ to $99.9 \%)$ ) (table 2). Cure was $93.8 \%(15 / 16)$ in the women who received azithromycin and $100 \%(20 / 20)$ in the women who received doxycycline (exact test $\mathrm{p}=0.444)$.

\section{Oropharyngeal CT and viability before treatment (week 0)}

At week -1, two hundred and forty-one women were oropharyngeally tested and $n=30(12.4 \%)$ tested positive for oropharyngeal CT. Of the $\mathrm{n}=30$ women diagnosed with oropharyngeal CT at week $-1, n=15$ were oropharyngeal CT positive at the subsequent visit at week 0 (table 1). Of the 211 women who tested negative at week $-1, \mathrm{n}=4(1.9 \%)$ were oropharyngeally positive at week 0 . Of the 319 women who were oropharyngeally untested at week $-1, \mathrm{n}=27(8.5 \%)$ were oropharyngeally CT positive at week 0 .

Thus, at week 0 , in total $46(8.8 \%)$ women were oropharyngeal CT positive. Of these, $26.1 \%(12 / 46)$ had viable CT, that is, tested V-PCR positive. Of the 12 women with viable CT at week 0 , one tested CT oropharyngeal positive at week 4 by NAAT; in fact she also tested positive at weeks 8 and 12 . 
Table 1 Proportions of oropharyngeal CT test results at week 0 (enrolment, just prior to treatment) by the preceding week -1 clinic diagnoses (interval 9 days) in 560 women, FemCure

\begin{tabular}{clc}
\hline & \multicolumn{2}{l}{ Week 0 (enrolment, treatment) } \\
\cline { 2 - 3 } Week -1 (clinic diagnosis) & $\mathrm{nhCT}-$ & PhCT+ \\
\cline { 2 - 3 } & $\mathbf{n}(\%)$ & $\mathrm{n}(\%)$ \\
\hline Total: $\mathrm{n}=560$ & $514(91.8)$ & $46(8.2)$ \\
PhCT+ $(\mathrm{n}=30)$ & $15(50.0)^{*}$ & $15(50.0)$ \\
PhCT- $(\mathrm{n}=211)$ & $207(98.1)$ & $4(1.9)$ \\
\hline PhCT untested $(\mathrm{n}=319)$ & $292(91.5)$ & $27(8.5)$ \\
\hline
\end{tabular}

*Indicates proportion of spontaneous clearance.

$\mathrm{CT}$, Chlamydia trachomatis; $\mathrm{Ph}$, oropharyngeal; $\mathrm{PhCT}+1-$, oropharyngeal positive or negative test result.

\section{Oropharyngeal CT after treatment at weeks 4, 8 and 12}

Ten women had an oropharyngeal CT positive test after treatment. One woman was positive at all post-treatment visits; she reported receptive oral sex during complete follow-up. Nine women were positive at a single time point only; $\mathrm{n}=2$ at week 4 , $\mathrm{n}=1$ at week $8, \mathrm{n}=6$ at week 12 visit. The proportion of oropharyngeal CT positive was between $0.5 \%$ and $1.6 \%$ between weeks 4 and 12 (table 2).

\section{DISCUSSION}

This is the first prospective study in women evaluating the trajectory of oropharyngeal CT infections from diagnosis to pretreatment, and until 12 weeks after treatment. We assessed spontaneous clearance and cure after standard treatment for anogenital CT infections, in women attending Dutch STI clinics.

Spontaneous oropharyngeal CT clearance was 50\% (95\% CI $31.3 \%$ to $68.7 \%$ ) after a median of 9 days after diagnosis of oropharyngeal CT in 30 women. This is similar to results in seven women showing $57.1 \%$ with a median follow-up of 10 days, ${ }^{8}$ and slightly higher than the $36.4 \%$ observed using RNAbased testing in 55 women in a median follow-up of 9 days. $^{6}$ The proportion of spontaneous clearance of oropharyngeal CT is much higher than we observed for vaginal CT $(6.0 \%$, $95 \%$ CI $4.2 \%$ to $8.4 \%)$ and rectal CT $(15.8 \%, 95 \%$ CI $10.8 \%$ to $21.8 \%) .{ }^{16}$ A possible explanation is the lower initial CT bacterial load at the oropharyngeal site compared with the vaginal and the rectal site, ${ }^{7}$ because lower initial load is associated with oropharyngeal CT clearance. ${ }^{68}$ Of those women who remained CT positive at the oropharyngeal site at week 0 , three quarters had non-viable CT only.

Cure was high for both azithromycin and doxycycline. Four weeks after treatment, $97.2 \%$ of women were negative for oropharyngeal CT. Proportions of cure were similar to those in azithromycin-treated vaginal CT (93.5\% (95\% CI 90.1\% to $96.1 \%)$ ), in doxycycline-treated vaginal CT $(95.4 \%$ (95\% CI $90.9 \%$ to $98.2 \%)$ ) and in doxycycline-treated rectal CT $(95.5 \%$ (95\% CI $91.0 \%$ to $98.2 \%)$ ); and higher than in azithromycintreated rectal CT $(78.5 \%$ (95\% CI $72.6 \%$ to $83.7 \%)) .{ }^{17}$ One woman was positive at all follow-up visits until week 12 ; she had oropharyngeal viable CT at week 0 and was untested at week -1 ; she reported receptive oral sex during follow-up.

A substantial proportion $(8.5 \%)$ of women with vaginal or rectal CT, and who were not tested at the oropharynx at week -1 , turned out to have oropharyngeal CT (at week 0 ), of whom almost a third had viable CT. Since vaginal CT is a risk factor for having oropharyngeal $\mathrm{CT}^{6}{ }^{6}$ the proportion of all women attending STI clinics with oropharyngeal CT may be lower than observed in this study. Phillips et al showed among MSM with oropharyngeal chlamydia, that nearly three-quarters had chlamydia DNA detected in saliva, but viability was not assessed. ${ }^{18}$ The proportion of positive women with viable oropharyngeal CT was $26.1 \%(12 / 46)$, which is lower than proportions of viable CT that we observed in vaginally $(94.0 \%-96.4 \%)$ and in rectally CT-infected women $(58.0 \%-66.5 \%) .{ }^{17}$ Although the proportion with viable oropharyngeal CT is relatively small, it may represent relevant infections for ongoing transmission to a sexual partner via oral sex, ${ }^{19}$ but possibly also to the own rectal site, via the gastrointestinal canal. ${ }^{20}$ After treatment, following $>425$ women until week 12 , only few women tested positive and most only at a single time point. The proportion of positive after treatment was between $0.5 \%$ and $1.6 \%$, in line with the estimated proportion of oropharyngeal CT in women $(0.2 \%$ $3.2 \%$; median $1.7 \%)^{5}$

In regular care practice, oropharyngeal CT testing is not routinely performed. Thus, oropharyngeal single-site CT infections (ie, without concurrent vaginal or rectal infection) largely remain untreated in women. Our study did not include participants with single oropharyngeal CT at week -1 , precluding analyses on single infections. However, single-site oropharyngeal CT spontaneous clearance has previously been found higher than concomitant oropharyngeal CT infections, ${ }^{6}$ possibly due to lower initial bacterial load. ${ }^{8}$ Still, in the STI clinic female population, part of the women with oropharyngeal CT will have vaginal CT. These women are standard tested for vaginal CT, and treated when positive, thereby as well treating a possible concurrent oropharyngeal CT. Altogether, the current study does not provide support for routine oropharyngeal CT testing in women who are already being tested for vaginal (or rectal) infection.

Table 2 Proportions of oropharyngeal test results after regular treatment at weeks 4,8 and 12 by the preceding week 0 (enrolment, just prior to treatment) test result, FemCure

\begin{tabular}{|c|c|c|c|c|c|c|c|c|c|}
\hline \multirow{2}{*}{$\begin{array}{l}\text { Week } 0 \text { (enrolment, } \\
\text { pretreatment)\# }\end{array}$} & $\begin{array}{l}\text { Tested at } \\
\text { week } 4\end{array}$ & $\begin{array}{l}\text { Week 4: } \\
\text { PhCT- }\end{array}$ & $\begin{array}{l}\text { Week 4: } \\
\text { PhCT+ }\end{array}$ & $\begin{array}{l}\text { Tested at } \\
\text { week } 8\end{array}$ & $\begin{array}{l}\text { Week 8: } \\
\text { PhCT- }\end{array}$ & $\begin{array}{l}\text { Week 8: } \\
\text { PhCT+ }\end{array}$ & $\begin{array}{l}\text { Tested at } \\
\text { week } 12\end{array}$ & $\begin{array}{l}\text { Week 12: } \\
\text { PhCT- }\end{array}$ & $\begin{array}{l}\text { Week 12: } \\
\text { PhCT+ }\end{array}$ \\
\hline & $N$ & $n(\%)$ & $n(\%)$ & $\mathrm{N}$ & n (\%) & n (\%) & $\mathrm{N}$ & $n(\%)$ & n (\%) \\
\hline Total & 449 & $446(99.3)$ & $3(0.7) a$ & 433 & 431 (99.5) & $2(0.5) a$ & 427 & $420(98.4)$ & $7(1.6) b$ \\
\hline PhCT $-(n=514)$ & 413 & 411 (99.5) & $2(0.5) a$ & 397 & $396(99.5)$ & $1(0.5) \mathrm{a}$ & 391 & 386 (98.7) & $5(1.3) c$ \\
\hline $\mathrm{PhCT}+(\mathrm{n}=46)$ & 36 & $35(97.2)^{*}$ & $1(2.8) \mathrm{a}$ & 36 & $35(97.2)$ & 1 (2.8)a & 36 & 34 (94.4) & $2(5.6) c$ \\
\hline
\end{tabular}

a: All reported recent (receptive) oral sex.

$b: \mathrm{n}=5$ reported recent (receptive) oral sex.

c: $n=1$ reported recent (receptive) oral sex.

*Indicates 'cure'.

$\mathrm{CT}$, Chlamydia trachomatis; $\mathrm{Ph}$, oropharyngeal; $\mathrm{PhCT}+$-, oropharyngeal positive or negative test result. 
This study has several limitations. (1) As in all human clearance studies, the moment of infection was unknown. (2) The exact day of clearance or cure is unknown, because we did not collect daily samples. (3) Clearance may differ by genotype, ${ }^{21} 22$ but genotyping was not performed on the diagnosis, at the week -1 , study samples. Genotyping would also be valuable to exclude reinfections, if these were with other genotypes. (4) Possibly, using a one time point test to assess spontaneous clearance or cure could have resulted in detecting false-negative or false-positive results. ${ }^{23-25}$ 'On off effects' (ie, a positive and negative test result in the same sample) might occur in samples with a low bacterial load around the detection limit, which may be more often the case in oropharyngeal CT infections. (5) The representativeness of our study is unknown. In the FemCure study, women with high education, women without a history of STI and non-Western migrant women were under-represented compared with all STI clinic women with CT infection. ${ }^{26}$ Also, STI clinic populations may not represent the general population.

To conclude, this study contributes to the growing knowledge on oropharyngeal CT. Most women diagnosed with vaginal or rectal chlamydia are not tested for CT in the oropharynx; yet $8.5 \%$ of these women tested NAAT positive for CT in the oropharynx when returning for CT treatment. However, we demonstrate that spontaneous clearance of oropharyngeal CT is substantial and higher than what is known for vaginal or rectal CT. The cure rate after regular treatment for anorectal CT infections is very high, and similar to that for vaginal CT. Our data suggest that routine universal oropharyngeal CT testing in all women, who are already tested for vaginal (or rectal CT), is of questionable importance.

\section{Key messages}

- Most women diagnosed with vaginal or rectal chlamydia are not tested for Chlamydia trachomatis (CT) in the pharynx; $8.5 \%$ of these women tested nucleic acid amplification test (NAAT) positive for CT in the oropharynx.

- Of women who tested NAAT positive for CT in the oropharynx, $26.1 \%$ had viable CT.

- Fifty per cent of women tested NAAT positive for chlamydia (CT) in the oropharynx were negative after a median 9 days, indicating spontaneous clearance.

- Nearly all (97.2\%) women tested NAAT positive for CT in the oropharynx cleared CT 4 weeks after receiving azithromycin or doxycycline.

\section{Author affiliations}

${ }^{1}$ Department of Health Promotion, Care and Public Health Research Institute (CAPHRI), Maastricht University Medical Center (MUMC+), Maastricht, The Netherlands

${ }^{2}$ Department of Sexual Health, Infectious Diseases, and Environmental Health, Public Health Service South Limburg, Heerlen, Limburg, The Netherlands ${ }^{3}$ Department of Medical Microbiology, Care and Public Health Research Institute (CAPHRI), Maastricht University Medical Center (MUMC+), Maastricht, The Netherlands

${ }^{4}$ Department of Public Health, Sexual Health Centre, Public Health Service Rotterdam-Rijnmond, Rotterdam, The Netherlands

${ }^{5}$ Department of Public Health, Erasmus MC — University Medical Center Rotterdam, Rotterdam, The Netherlands

${ }^{6}$ Epidemiology and Surveillance Unit, Centre for Infectious Disease Control, National Institute of Public Health and the Environment (RIVM), Bilthoven, The Netherlands

${ }^{7}$ Department of Infectious Diseases, Public Health Service Amsterdam, Amsterdam, The Netherlands
${ }^{8}$ Department of Dermatology, Amsterdam Institute for Infection and Immunity (AI\&II), location Academic Medical Centre, Amsterdam UMC, University of Amsterdam, Amsterdam, The Netherlands

${ }^{9}$ Department of Internal Medicine, Amsterdam Institute for Infection and Immunity (Al\&II), location Academic Medical Centre, Amsterdam UMC, University of Amsterdam, Amsterdam, The Netherlands

${ }^{10}$ Department of Social Medicine, University of Maastricht, Maastricht, The Netherlands

\section{Handling editor Jonathan Ross}

Acknowledgements We are grateful to the staff at the Public Health Service (GGD) South Limburg: Lisanne Eppings, Dr Ronald van Hoorn, Maria Mergelsberg, Mandy Sanders, Emily Suijlen, Bianca Penders, Helen Sijstermans and Ine de Bock; the staff at GGD Rotterdam-Rijnmond: Astrid Wielemaker, Angie Martina, Roselyne Uwimana, Mieke Illidge, Klaas de Ridder and Bram Meima for data management; and the staff at GGD Amsterdam: Titia Heijman, Dieke Martini, Myra van Leeuwen, Claudia Owusu, Jacqueline Woutersen, Princella Felipa, Mayam Amezian, Arjdal Khadija and Iris Deen, who were involved in the logistics and inclusion, and Martijn van Rooijen for data management. We also thank the staff at the laboratories of Medical Microbiology of the Maastricht University Medical Center, especially Judith Veugen, Laura Saelmans and Kevin Janssen. Also, we thank the staff of the microbiological laboratory of the GGD Amsterdam: Esther Heuser and Michelle Himschoot.

Contributors NHTMDM coordinated the study, performed the statistical analyses, wrote and drafted the paper. NHTMDM, CJPAH, PW, HMG, SMB, MSvdL and HDV designed the study. ML and PW coordinated the laboratory data collection and testing. All authors were involved in the study design, critically edited the manuscript and approved the final manuscript.

Funding This study is funded by a grant from the governmental organisation Netherlands Organization for Health Research and Development (ZonMW Netherlands) (registration numbers 50-53000-98-109 and 52-2008-002).

Competing interests None declared.

\section{Patient consent for publication Not required.}

Ethics approval All participants provided written informed consent. This study was approved by the Medical Ethics Review Committee from the Maastricht University Medical Center, Maastricht, Netherlands (NL51358.068.15/METC153020, 20-012016) and monitored by the Clinical Trial Centre Maastricht.

Provenance and peer review Not commissioned; externally peer reviewed.

Data availability statement Data are available upon reasonable request. All data relevant to the study are included in the article or uploaded as supplementary information. Please send an email to helen.sijstermans@ggdzl.nl.

\section{ORCID iDs}

Nicole H T M Dukers-Muijrers http://orcid.org/0000-0003-4896-758X

Hannelore M Götz http://orcid.org/0000-0002-1236-6224

Sylvia M Bruisten http://orcid.org/0000-0003-4897-4261

\section{REFERENCES}

1 Unemo M, Bradshaw CS, Hocking JS, et al. Sexually transmitted infections: challenges ahead. Lancet Infect Dis 2017;17:e235-79.

2 Rowley J, Vander Hoorn S, Korenromp E, et al. Chlamydia, gonorrhoea, trichomoniasis and syphilis: global prevalence and incidence estimates, 2016. Bull World Health Organ 2019;97:548-62.

3 Haggerty CL, Gottlieb SL, Taylor BD, et al. Risk of sequelae after Chlamydia trachomatis genital infection in women. $J$ Infect Dis 2010;201 Suppl 2:134-55.

4 Hoenderboom BM, van Benthem BHB, van Bergen JEAM, et al. Relation between Chlamydia trachomatis infection and pelvic inflammatory disease, ectopic pregnancy and tubal factor infertility in a Dutch cohort of women previously tested for chlamydia in a chlamydia screening trial. Sex Transm Infect 2019;95:300-6.

5 Chan PA, Robinette A, Montgomery M, et al. Extragenital infections caused by Chlamydia trachomatis and Neisseria gonorrhoeae: a review of the literature. Infect Dis Obstet Gynecol 2016;2016:5758387

6 van Rooijen MS, van der Loeff MFS, Morré SA, et al. Spontaneous pharyngeal Chlamydia trachomatis RNA clearance. A cross-sectional study followed by a cohort study of untreated STI clinic patients in Amsterdam, the Netherlands. Sex Transm Infect 2015;91:157-64.

7 Wijers JNAP, Dukers-Muijrers NHTM, van Liere GAFS, et al. Men and women have an equal oropharyngeal and anorectal Chlamydia trachomatis bacterial load: a comparison of three anatomic sites. J Infect Dis 2019:pii: jiz668.

8 van Liere GAFS, Hoebe CJPA, Dirks JA, et al. Spontaneous clearance of urogenital, anorectal and oropharyngeal Chlamydia trachomatis and Neisseria gonorrhoeae in women, MSM and heterosexual men visiting the STI clinic: a prospective cohort study. Sex Transm Infect 2019;95:505-10. 
9 Yeruva L, Spencer N, Bowlin AK, et al. Chlamydial infection of the gastrointestinal tract: a reservoir for persistent infection. Pathog Dis 2013;68:88-95.

10 Dukers-Muijrers NHTM, Schachter J, van Liere GAFS, et al. What is needed to guide testing for anorectal and pharyngeal Chlamydia trachomatis and Neisseria gonorrhoeae in women and men? evidence and opinion. BMC Infect Dis 2015; 15:533.

11 Dukers-Muijrers NHTM, Wolffs PFG, Eppings L, et al. Design of the FemCure study: prospective multicentre study on the transmission of genital and extra-genital Chlamydia trachomatis infections in women receiving routine care. BMC Infect Dis 2016;16:381.

12 Lanjouw E, Ouburg S, de Vries HJ, et al. 2015 European guideline on the management of Chlamydia trachomatis infections. Int J STD AIDS 2016;27:333-48.

13 National Coordination for Infection Control (LCI). Procedure for the sexual health consultation. Available: https://lci.rivm.nl/draaiboeken/consult-seksuele-gezondheid [Accessed 4 Sep 2019].

14 Janssen KJH, Hoebe CJPA, Dukers-Muijrers NHTM, et al. Viability-PCR shows that NAAT detects a high proportion of DNA from non-viable Chlamydia trachomatis. PLoS One 2016;11:e0165920.

15 Janssen KJH, Wolffs P, Lucchesi M, et al. Assessment of rectal Chlamydia trachomatis viable load in women by viability-PCR. Sex Transm Infect 2020;96:85-8.

16 Dukers-Muijrers NHTM, Janssen KJH, Hoebe CJPA, et al. Spontaneous clearance of Chlamydia trachomatis accounting for bacterial viability in vaginally or rectally infected women (FemCure). Sex Transm Infect 2020;96:541-8.

17 Dukers-Muijrers NHTM, Wolffs PFG, De Vries H, et al. Treatment effectiveness of azithromycin and doxycycline in uncomplicated rectal and vaginal Chlamydia trachomatis infections in women: a multicenter observational study (FemCure). Clin Infect Dis 2019;69:1946-54.
18 Phillips TR, Fairley CK, Maddaford K, et al. Bacterial load of Chlamydia trachomatis in the posterior oropharynx, tonsillar Fossae, and saliva among men who have sex with men with untreated oropharyngeal Chlamydia. J Clin Microbiol 2019;58:pii: e0137519.

19 Barbee LA, Khosropour CM, Dombrowski JC, et al. An estimate of the proportion of symptomatic gonococcal, chlamydial and non-gonococcal non-chlamydial urethritis attributable to oral sex among men who have sex with men: a case-control study. Sex Transm Infect 2016:92:155-60.

20 Yeruva L, Spencer N, Bowlin AK, et al. Chlamydial infection of the gastrointestinal tract: a reservoir for persistent infection. Pathog Dis 2013;68:88-95.

21 Geisler WM, Black CM, Bandea Cl, et al. Chlamydia trachomatis OmpA genotyping as a tool for studying the natural history of genital chlamydial infection. Sex Transm Infect 2008:84:541-4.

22 Götz HM, Bom RJM, Wolfers MEG. Use of Chlamydia trachomatis high-resolution typing: an extended case study to distinguish recurrent or persistent infections from new infection. STI, 2013.

23 Dukers-Muijrers NHTM, Morré SA, Speksnijder A, et al. Chlamydia trachomatis testof-cure cannot be based on a single highly sensitive laboratory test taken at least 3 weeks after treatment. PLoS One 2012;7:e34108.

24 Price MJ, Ades AE, Soldan K, et al. The natural history of Chlamydia trachomatis infection in women: a multi-parameter evidence synthesis. Health Technol Assess 2016;20:1-250.

25 Lewis J, Price MJ, Horner PJ, et al. Genital Chlamydia trachomatis infections clear more slowly in men than women, but are less likely to become established. J Infect Dis 2017;216:237-44.

26 Dukers-Muijrers NHTM, Heijman T, Götz HM, et al. Participation, retention, and associated factors of women in a prospective multicenter study on Chlamydia trachomatis infections (FemCure). PLoS One 2020;15:e0230413. 